\title{
Cricoarytenoid arthritis: a cause of acute upper airway obstruction in rheumatoid arthritis
}

\author{
[L'arthrite crico-aryténoïdienne : une cause d'obstruction des voies respiratoires \\ supérieures dans l'arthrite rhumatoïde]
}

Jacelyn Kolman MD, Ian Morris MD FRCPC FACEP DABA

Purpose: To report acute upper airway obstruction due to cricoarytenoid arthritis, a well known but uncommon complication of rheumatoid arthritis.

Clinical features: We report the case of a 70-yr-old female scheduled for a colostomy who had been suffering from rheumatoid arthritis for 17 years. Preoperative history and physical examination revealed no cardiopulmonary compromise. Anesthesia was induced while an assistant immobilized the cervical spine and an atraumatic intubation was performed. Surgery was uneventful. Muscle paralysis was reversed, demonstrated by normalization of the train-of-four response, and the patient was extubated awake. Shortly postextubation, the patient developed inspiratory stridor, which disappeared after a second dose of neostigmine. The patient was transported to the postanesthesia care unit. Just prior to arrival the patient once again developed inspiratory stridor, became distressed, and oxygen saturation decreased. Direct laryngoscopy followed by a nasal fibreoptic examination of the larynx was performed. Cricoarytenoid arthritis secondary to rheumatoid arthritis with airway compromise was diagnosed. An uneventful awake tracheostomy was performed. The patient was discharged on day ten with a colostomy and a tracheostomy in place. One month postdischarge the patient's trachea was decannulated. On follow-up, a normal voice and mobile cords were observed.

Conclusion: Cricoarytenoid arthritis is an infrequent complication of rheumatoid arthritis. A thorough history and physical examination are necessary to recognize signs and symptoms of cricoarytenoid arthritis. Prompt recognition of airway obstruction due to cricoarytenoid arthritis is essential for appropriate management.

Objectif : Présenter un cas d'obstruction des voies respiratoires supérieures provoquée par l'arthrite crico-aryténoïdienne, une complication rare, mais bien connue, de l'arthrite rhumatoïde.

Éléments cliniques : Il s'agit d'une femme de 70 ans, souffrant d'arthrite rhumatoïde depuis I7ans, qui devait subir une colostomie.
L'anamnèse préopératoire et l'examen physique n'ont révélé aucune atteinte cardio-pulmonaire. L'anesthésie a été induite pendant l'immobilisation de la colonne cervicale par un assistant, puis l'intubation atraumatique a été réalisée. L'intervention chirurgicale s'est bien déroulée. La paralysie musculaire a été renversée, prouvée par la normalisation de la réponse en train-de-quatre, et l'extubation vigile a été pratiquée. Peu après, un stridor s'est développé et a disparu à la suite d'une seconde dose de néostigmine. La patiente a été transportée à la salle de réveil. Juste avant l'arrivée, le stridor est apparu de nouveau, accompagné de détresse et d'une baisse de la saturation en oxygène. On a procédé à une laryngoscopie directe suivie d'un examen fibroscopique nasal du larynx. L'arthrite crico-aryténoïdienne secondaire à l'arthrite rhumatoïde, avec obstruction des voies respiratoires, a été diagnostiquée. Une trachéotomie vigile a été faite, sans incident. La patiente a quitté l'hôpital au dixième jour avec une colostomie et une trachéostomie en place. La canule trachéale a été enlevée un mois après. La voix était normale et les cordes vocales mobiles lors du suivi.

Conclusion : L'arthrite crico-aryténoïdienne est une complication rare de l'arthrite rhumatoïde. Une anamnèse fouillée et un examen minutieux sont nécessaires pour en reconnaître les signes et les symptômes. Le diagnostic rapide d'obstruction des voies aériennes causée par l'arthrite crico-aryténoïdienne est essentiel au traitement approprié.

A NESTHESIOLOGISTS frequently care for patients with rheumatoid disease. Any synovial surface in the body can be affected and females are in the majority. ${ }^{1-3}$ Comprehensive assessment of the potential hazards facilitates careful anesthetic management. ${ }^{2-4}$ We report a case of acute upper airway obstruction due to cricoarytenoid arthritis, a well- known but rare complication of rheumatoid arthritis.

From the Department of Anesthesia, Queen Elizabeth Health Centre, Dalhousie University, Halifax, Nova Scotia, Canada.

Address correspondence to: Dr. Jacelyn Kolman, 6059 South Street, Halifax, Nova Scotia B3H 1S9, Canada. Phone: 902-422-9137; Fax:

902-423-9454; E-mail: j_kolman@hotmail.com

Accepted for publication November 26, 2002.

Revision accepted May 27, 2002. 


\section{Case report}

A 70 -yr-old female, height $148 \mathrm{~cm}$, weight $45 \mathrm{~kg}$, with a rectovaginal fistula secondary to radiotherapy postrectal cancer resection was scheduled for a colostomy. She had been suffering from rheumatoid arthritis for 17 years.

The patient had arthritic involvement of her shoulders, hands, knees and hips, and had previously undergone bilateral total hip replacements and one total knee replacement. The patient had seen her rheumatologist one month prior to surgery. Her current medications included misoprostol, diclofenac and folic acid. She had been taking methotrexate but it had been discontinued one month prior to her surgery. She was an ex-smoker and denied any cardiovascular, respiratory and joint symptoms. The preoperative physical examination revealed normal cardiovascular and respiratory systems. Examination of the airway revealed an edentulous mouth with good mouth opening, full range of motion of her neck with no discomfort elicited, and no obvious temporomandibular joint (TMJ) involvement. Her Mallampati classification was II.

Anesthesia was induced with $100 \mu \mathrm{g}$ of fentanyl, 80 $\mathrm{mg}$ of propofol and $40 \mathrm{mg}$ of rocuronium. The patient's head was held by an assistant to prevent excessive movement during intubation. The laryngoscopic view was Cormack grade I and a 7.5 endotracheal tube was inserted atraumatically. No abnormality of the vocal cords was noted. The operation lasted $90 \mathrm{~min}$ and was uneventful. Muscle relaxation was reversed using 2.5 $\mathrm{mg}$ neostigmine and $0.4 \mathrm{mg}$ glycopyrrolate following which neuromuscular stimulation revealed no fade of train-of-four. The patient resumed spontaneous ventilation, awoke and was extubated after eye opening and arm movement occurred. Initially, she appeared comfortable and demonstrated sustained muscle movement. However, after being transferred onto the stretcher, she began to have inspiratory stridor and became dyspneic. Oxygen via facemask was provided and additional neostigmine, $2 \mathrm{mg} i \mathrm{v}$, was administered despite the absence of clinical signs of inadequate reversal. The stridor rapidly disappeared. Her oxygen saturation was 98\%. The patient was then transferred to the postanesthesia care unit (PACU), awake and breathing spontaneously, with supplemental oxygen at $3 \mathrm{~L} \cdot \mathrm{min}^{-1}$ by nasal prongs. Immediately prior to arrival in the PACU, inspiratory stridor recurred. Vital signs and oxygen saturation were initially normal. Oxygen was provided by facemask in the PACU. The stridor continued and the patient became distressed. Her oxygen saturation fell to $85 \%$. Neostigmine, $\mathrm{l} \mathrm{mg}$ iv, was given without improvement. Morphine, $2 \mathrm{mg} i \mathrm{v}$, was administered for sedation in the event that anxiety, with increased inspiratory effort, could have contributed to the stridor. The stridor persisted and ventilation was assisted by bag valve mask with $100 \%$ oxygen. The patient's muscle strength was normal as assessed by hand grip and no floppy muscle movement was noted. Propofol, $30 \mathrm{mg}$ $i v$, was administered and direct laryngoscopy was performed with minimal neck movement. The true vocal cords appeared white, thickened and poorly mobile with a decreased glottic opening. The arytenoids were in normal position. No edema or trauma of the larynx or pharynx was noted. Spontaneous ventilation was maintained and the stridor again subsided. A diagnosis of cricoarytenoid arthritis with decreased vocal cord mobility secondary to rheumatoid arthritis was entertained and an urgent consultation to the ear-nosethroat (ENT) service was requested to confirm the diagnosis and advise regarding management. The patient reawakened without stridor. When fully awake she was again breathing comfortably with a respiratory rate of 20 breaths. $\mathrm{min}^{-1}$ and oxygen saturation of $99 \%$ on $3 \mathrm{~L} \cdot \mathrm{min}^{-1}$ oxygen nasal prongs. A few minutes later, however, inspiratory stridor suddenly returned. The ENT consultant arrived and performed a fibreoptic examination of the larynx under topical anesthesia via the right nostril. Again, minimal abduction of the vocal cords was demonstrated with a 2 -mm glottic opening. No evidence of trauma to the arytenoid joints was noted. A diagnosis of paramedian vocal cord fixation secondary to rheumatoid arthritis was made. The ENT consultant felt an awake tracheostomy under local anesthetic was indicated to ensure a patent airway and this was performed under controlled circumstances. A \#6 cuffed Shiley (fenestrated) tracheostomy tube was placed. The patient tolerated the procedure well and demonstrated remarkably normal speech.

After the operation, the patient was restarted on methotrexate. Ten days after admission, the patient was discharged with the tracheostomy in place because of persisting immobilization of the vocal cords.

The patient was seen by the ENT consultant in follow-up one month after discharge. A flexible endoscopic examination at that time revealed normal mobile cords with no edema or masses. The tracheostomy was removed. Four weeks later the patient demonstrated a healed tracheostomy site, a normal voice and mobile cords.

\section{Discussion}

Rheumatoid arthritis is a chronic inflammatory disease that affects multiple joints. The articular symptoms are usually the predominant feature, although multiple systemic manifestations can also occur. ${ }^{2,3}$ Ankylosis 
and obliteration of the cricoarytenoid joint can occur and lead to life threatening airway obstruction. ${ }^{5-7}$

Involvement of the cricoarytenoid joint has been reported in $26 \%-86 \%$ of patients with rheumatoid arthritis and can be asymptomatic. ${ }^{8,9}$ Furthermore, the severe discomfort characteristic of rheumatoid disease can lead the clinician to overlook cricoarytenoid involvement. ${ }^{5,10,11}$

Although first reported in 1880, greater attention has been paid to cricoarytenoid arthritis following Montgomery's 1955 publication on rheumatoid arthritis of the larynx. ${ }^{10}$

The cricoarytenoid joint is formed by the articulation of the arytenoid and cricoid cartilages at the lateral aspect of the posterior lamina of the cricoid cartilage. ${ }^{12}$ The cricoarytenoid joint is a true diarthrodial joint, having both a synovial lining and a fluidfilled space within a fibrous bursa. Functionally, the joint can be described as a ball and socket and has three movements: a rocking or rotating movement around the axis, a linear glide parallel to this axis and a pivoting motion ${ }^{12,13}$ (Figure). The joint controls abduction and adduction of the vocal cords thereby facilitating respiration, as well as protecting the airway and permitting phonation. ${ }^{9}, 14$

Any synovial articulation can potentially be affected by rheumatoid arthritis. Increased cellularity of the synovium occurs leading to synovial inflammation. The inflamed synovial tissue covers the articulating surfaces. The tissue matures, becoming less vascular and more fibrotic. Pannus (hyperplastic synovial tissue) is formed and erodes cartilage, subchondral bone, articular capsule and adjacent ligaments. The joint space obliterates and contraction of the fibrous tissue causes deformity and ankylosis of the joint. ${ }^{12,15}$

Acute cricoarytenoid arthritis presents as a sensation of a foreign body, fullness or tension in the throat which is aggravated by swallowing or speaking. Other findings include hoarseness, odynophagia and pain with speaking or coughing. Pain radiating to the ear(s) can occur due to the cricoarytenoid joint sensory innervation via the glosssopharyngeal and vagus nerves. Dyspnea is directly proportional to the amount of laryngeal edema and immobilization of the arytenoids. Tenderness of the thyroid cartilage or superior thyroid cornua may be present. Stridor can occur and increase in severity during sleep or sedation. Direct laryngoscopic examination reveals bright red swelling over the arytenoids with normal vocal cords. Bowing of the vocal cords during inspiration may be observed. ${ }^{11,12,16}$

Chronic cricoarytenoid arthritis may be asymptomatic. Decompensation of the chronic state can occur due to laryngeal manipulation or infection. Asthma or

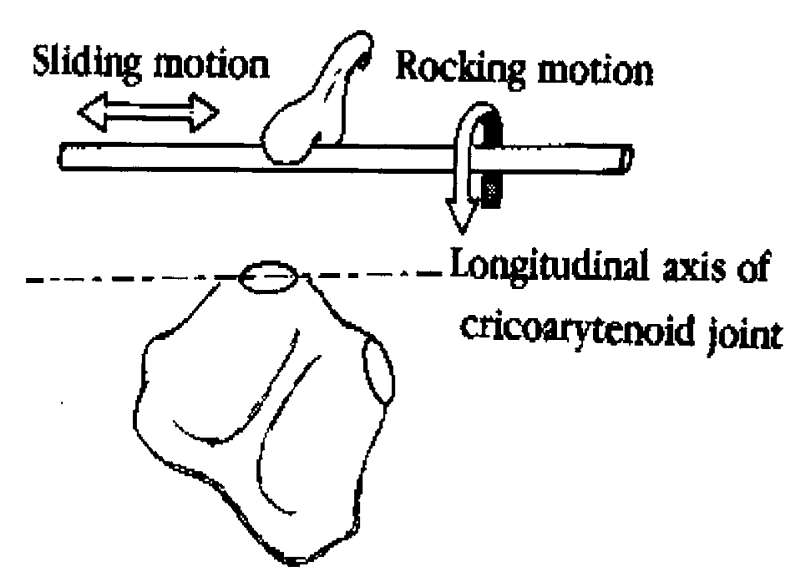

FIGURE Functional potential at the cricoarytenoid joint (reprinted with permission from Dickson DR, Dickson W. Phonation. In: Dickson DR, Dickson W (Eds.). Anatomical and Physiological Bases of Speech. Little, Brown and Company, 1982: 156.

chronic bronchitis is frequently misdiagnosed. Symptoms include dyspnea, hoarseness and stridor. Mucosa over the arytenoids is rough or thickened and a narrow vocal chink is seen on direct laryngoscopy. No edema or redness is noted and the larynx appears normal.

Cricoarytenoid arthritis occurs most commonly in rheumatoid disease. Other etiologies include gout, disseminated lupus erythematosis, scleroderma, Tietze's syndrome, upper respiratory tract infections, trauma, vocal cord tumours, recurrent laryngeal nerve paralysis and immobilization of the cricoarytenoid joint due to long standing paralysis of intrinsic laryngeal muscles. ${ }^{5,17}$

The diagnosis of cricoarytenoid arthritis can be difficult. Symptoms can be vague, absent or masked by concomitant joint involvement. The diagnosis is confirmed by fibreoptic laryngoscopic examination. ${ }^{18}$ In the non- emergent setting, pulmonary function studies are useful to document functional compromise and progression. On the flow-volume loop a fixed or variable pattern of extrathoracic upper airway obstruction can be seen. ${ }^{18}$ Radiologic evaluation using low-voltage neck radiography and computed tomography can also be diagnostic.,19

Treatment of rheumatoid cricoarytenoid arthritis involves management of the systemic disease. ${ }^{9}$ Acute stage therapy includes voice rest, local heat, antiinflammatory medication and steroids. Systemic, topical or locally injected steroids are beneficial, although the value of high-dose steroids is controversial. ${ }^{18}$ 
Acute airway compromise requires prompt treatment if fatal upper airway obstruction is to be avoided. Intubation may be difficult. ${ }^{5-7}$ Tracheostomy has been life-saving and is the preferred treatment when the patient presents with stridor and bilateral midline arytenoid fixation..$^{5,6}$ Decannulation may be possible following remission. If chronic bilateral fixation of the vocal cords occurs in the adducted position, a unilateral arytenoidectomy and suturing of the ipsilateral cord in abduction can be performed.

Awareness of cricoarytenoid arthritis is necessary for optimal anesthetic management. A thorough preoperative evaluation is essential to determine cricoarytenoid joint disease. ${ }^{4}$ Rheumatoid involvement of the cervical spine and TMJ can further complicate airway management. In addition to history and physical examination, fibreoptic examination of the larynx and radiologic evaluation may be required. ${ }^{7}$ Avoidance of laryngeal injury is of utmost importance. If minimal cricoarytenoid joint involvement exists, use of a smaller-than-usual endotracheal tube is recommended. ${ }^{20}$ If the larynx is severely affected, oral intubation should be avoided altogether, if possible. ${ }^{4,5} \mathrm{~A}$ regional anesthetic technique may be a reasonable option. ${ }^{21}$ If a regional technique is not possible, a presurgical tracheostomy under local anesthesia may be a consideration. ${ }^{11,21}$

Airway obstruction can occur following extubation. Extubation should be performed when neuromuscular blockade is fully reversed and the patient is awake. Close observation following extubation is required and equipment should be readily available to manage the airway should obstruction occur. ${ }^{3}$ Narcotic analgesia should be used judiciously. ${ }^{2,3,11}$

In summary, cricoarytenoid involvement should be suspected in patients with rheumatoid arthritis, especially in those with long-standing disease. Absence of symptoms does not rule out cricoarytenoid joint involvement. Airway obstruction can occur and be potentially fatal. Tracheostomy remains the definitive treatment for airway obstruction caused by cricoarytenid arthritis.

\section{References}

1 Brazeau-Lamontagne L, Charlin B, Levesque RY, Lussier A. Cricoarytenoiditis: CT assessment in rheumatoid arthritis. Radiology 1986; 158: 463-6.

2 Skues MA, Welchew EA. Anaesthesia and rheumatoid arthritis. Anaesthesia 1993; 48: 989-97.

3 Jenkins LC, McGraw RW. Anaesthetic management of the patient with rheumatoid arthritis. Can Anaesth Soc J 1969; 16: 407-15.

4 Matti MV, Sharrock NE. Anesthesia on the rheumatoid patient. Rheum Dis Clin North Am 1998; 24: 19-34.
5 Phelps JA. Laryngeal obstruction due to cricoarytenoid arthritis. Anesthesiology 1966; 27: 518-22.

6 Kandora TF, Gilmore IM, Sorber JA, Rose FB, Matta II. Cricoarytenoid arthritis presenting as cardiopulmonary arrest. Ann Emerg Med 1985; 14: 700-2.

7 Bamshad M, Rosa U, Padda G, Luce M. Acute upper airway obstruction in rheumatoid arthritis of the cricoarytenoid joints. South Med J 1989; 82: 507-11.

8 Lofgren RH, Montgomery $W W$. Incidence of laryngeal involvement in rheumatoid arthritis. N Engl J Med 1962; 267: 193-5.

9 Bienenstock H, Ehrlich GE, Freyberg RH. Rheumatoid arthritis of the cricoarytenoid joint: a clinicopathologic study. Arthritis Rheum 1963; 6: 48-63.

10 Polisar IA. The crico-arytenoid joint: a diarthrodial articulation subject to rheumatoid arthritic involvement. Laryngoscope 1959; 69: 1129-64.

11 Grossman A, Martin JR, Root HS. Rheumatoid arthritis of the crico-arytenoid joint. Laryngoscope 1961; 71: 530-44.

12 Montgomery $W W$. Cricoarytenoid arthritis. Laryngoscope 1963; 73: 801-36.

13 Sellars I, Sellars S. Cricoarytenoid joint structure and function. J Laryngol Otol 1983; 97: 1027-34.

14 von Leden H, Moore P. The mechanics of the cricoarytenoid joint. Arch Otolaryngol 1961; 73: 63-72.

15 Bridger MWM, Jahn AF, van Nostrand AWP. Laryngeal rheumatoid arthritis. Laryngoscope 1980; 90: 296-303.

16 Woldorf NM, Pastore PN, Terz J. Rheumatoid arthritis of the cricoarytenoid joint. Arch Otolaryngol 1971; 93: 623-7.

17 Leicht MJ, Harrington TM, Davis DE. Cricoarytenoid arthritis: a cause of larygneal obstruction. Ann Emerg Med 1987; 16: 885-8.

18 Lynch JP III, Quint LE. Tracheobronchial and esophageal manifestations of systemic diseases. In: Cummings CW (Ed.). Otolaryngology Head and Neck Surgery, $3^{\text {rd }}$ ed. Missouri: Mosby-Year Book, Inc., 1998: 2343-67.

19 Jurik AG, Pedersen U. Rheumatoid arthritis of the crico-arytenoid and crico-thyroid joints: a radiological and clinical study. Clin Radiol 1984; 35: 233-6.

20 Funk D, Raymon F. Rheumatoid arthritis of the cricoarytenoid joints: an airway hazard. Anesth Analg 1975; 54: 742-5.

21 Gardner DL, Holmes F. Anaesthetic and postoperative hazards in rheumatoid arthritis. Br J Anaesth 1961; 33: 258-64. 